\title{
Science Education in Asia
}

\section{Iris Huang}

\section{Introduction}

Th i s p a p r o pen s with a discussion of some general characteristics of the Asian educational system and then provides a more complete description of science education in Mainland China and Taiwan. The paper concludes with a discussion of the issues and trends of science education in Mainland China and Taiwan.

\section{Characteristics of Asian Education}

Tradition, Westernization, centralization, and competition provide the context for understanding contemporary science education in Asia. Examinations and teachers are deeply rooted in the traditions of Asian countries, such as China with its five thousand years of history. The examination is viewed as a "fair" tool to select people. Even in ancient China, the civil service examinations offered ordinary people the opportunity to be selected for government position, and therefore they had the opportunity to improve their social position. With the exception of Mainland China, teachers enjoy a high social status in Asia. Traditionally, higher educational levels in Asia have been associated with upward mobility.

During the last century, tradition in Asia has been affected by Western influences. During the last one hundred years, many Asian countries such as Hong Kong, the Philippines, and Malaysia have become colonies of Western countries such as the United Kingdom, the United States, and Spain. These Western countries set up their education system in Asia; consequently, the organizational structure of education systems in parts of Asia are similar to those found in the West (Wu, 1990). A similar, although more indirect, influence is evident in countries like China, Japan, and Thailand, which were not colonized. These countries sent many of their outstanding students to Germany, the United Kingdom, and the United States to pursue advanced study in the areas of science, technology, policy, law, and so forth. Later these 
individuals rose to influential government and university positions so that many of the policies, organizations, and training approaches they implemented were influenced by Western culture. The U.S. higher education institutions continue to provide doctoral education for many Asian students. The proportion of doctoral degrees obtained in the United States vary substantially from country to country. For example, about 75 percent of the doctoral degrees earned by Taiwanese students are awarded by United States universities, whereas the percentage falls to 50 percent for students from Korea and 33 percent for students from China. Less than 4 percent of the doctoral degrees earned by Japanese students are awarded by U.S. universities (Johnson, 1993).

Throughout Asia, national governments control science education. With such a centralized system, teachers teach from standard textbooks and must reach curriculum goals established by the government.

Asian education is also characterized by competition. Most science teachers are under considerable pressure from students, school principals, parents, and themselves to assume the major responsibility for helping students pass the competitive entrance examinations required for entry into good high schools, colleges, or universities. In these entrance examinations, students who score higher may choose the more desirable schools. The competition for admission to universities and even to some prestigious high schools is truly fierce, because many applicants are competing for so few slots. The success rate of students taking the high school or university entrance exams determines the status of junior or senior high schools. Because of the competition for admission, students spend many hours studying after school in some type of private academic setting referred to as Bu-SieBen in Chinese and Jukus in Japanese. These private programs can also be very expensive.

Historical Background of Chinese Education

When the Ching (Manchu) Dynasty was overthrown in 1911, Dr. Sun Yat-sen, founder of the country, based the construction of the nation on the Three Principles of the People-namely, Nationalism, Democracy, and the People's Livelihood. Following these principles, a 
new education system was implemented. In the early days of the new education system, China remained an agricultural economy. At that time, a great majority of the population in the country was illiterate. Only after the National Army successfully defeated all the provincial warlords and reunified the entire nation in 1928 did the government begin to set up schools and enroll students in large numbers all over the country. However, because of the widespreading territory and voluminous population, success was not achieved overnight. The Japanese invasion of China and World War II caused heavy losses to the country. Soon after World War II ended in the fall of 1945 , a program was launched to rehabilitate the national education system. However, the rehabilitation effort did not last long. The Chinese Communists quickly expanded and the government of the Republic of China was relocated to Taiwan in 1949.

Science Education in Mainland China

From 1949 until the Sino-Soviet rift in 1960, China looked to the Soviet Union to provide models of pedagogy and content selection. Since the rift, China has been following a line that is "both autonomous and to some extent internationalist" (China Handbook Editorial Committee, 1983).

China has the largest education system in the world with some unique features that make it unlike that in any other country. The immense size of the country (geographically and demographically), the cultural traditions that shape pedagogy, the ideology of the state, and the rapidity with which changes have been taking place all contribute to the uniqueness of the Chinese educational system.

In 1985 the Central Committee of the Communist Party of China published a major review of education policy that emphasized the aims of improving the quality of the nation and producing as many skilled people as possible through restructuring the educational system to focus attention on improvements in agriculture, industry, defense, and science and technology. 
The Structure of Education System

Because of historical reasons, the structure of the education system varies in different parts of China, although the most common pattern is five years of primary school, three years of junior middle, and two years of senior middle $(5: 3: 2)$. In many parts of China the pattern is changing to a $6: 3: 3$ sequence.

\section{TABLE 1.}

\section{The School System of Mainland China}

\begin{tabular}{l|ccc}
\multicolumn{1}{c}{ Level } & $\begin{array}{c}\text { Numbers of Students } \\
\text { (in millions) }\end{array}$ & $\begin{array}{c}\text { Number of Schools } \\
\text { (in thousands) }\end{array}$ & $\begin{array}{c}\text { \% of Key } \\
\text { Schools }\end{array}$ \\
\hline Primary & 122 & 766 & 2 \\
Junior high & 39 & 72 & 8 \\
Senior high & 14 & 28 & 4 \\
Higher education & 0.62 & 1.1 & 9
\end{tabular}

Primary schools enroll virtually all urban and the majorigty of rural children. On average about one-third of these students fail to make the transition to lower secondary. Of those who do, over 30 percent fail to complete junior middle. By the end of the first of junior middle, less than 50 percent of an age group is enrolled. This drops to less than 13 percent for senior middle. Table 2 shows the enrollment rate of students ages 6 to 14 in Mainland China and Taiwan in 1990 (Lee, 1992). In 1990, 25 percent of senior middle graduates proceeded to university (Liu, 1992). External examinations are a feature of all the transition points in the system.

\section{TABLE 2.}

Enrollment of Students (ages 6-14) of Mainland China and Taiwan in 1989

\begin{tabular}{l|cc}
\multicolumn{1}{c}{ Country } & Male & Female \\
\hline Mainland China & $80 \%$ & $73 \%$ \\
Taiwan & $96.6 \%$ & $96.6 \%$
\end{tabular}


A system of "key schools" operates at national, provincial, country, and city levels. These schools are highly selective, and entrance to them is through competitive examinations. Such schools receive additional resources over and above those allocated to normal schools, typically two to three times as much money and one-third more staff. Transition rates within key schools and into higher education are normally very high, close to 100 percent into higher education and 85 percent into key universities. Currently, key schools constitute about 2 percent of primary schools, 8 percent of junior high schools, 3.8 percent of senior high schools, and 9 percent of universities (Wei et al., 1995).

Increasing emphasis is being placed on vocational, technical, and agricultural high schools. This is likely to increase the demand for science education (Wei et al., 1995).

\section{Science curriculum}

The curriculum in both junior and senior high schools is developed centrally. The People's Education Press (PEP) has the responsibility of compiling textbooks in accordance with the central guidelines. Recently, teachers have come to play an important role in curriculum development. New material now goes through a draft stage in which comments from teachers are encouraged.

Dual-level courses are being developed at the secondary level to accompany the restructuring of the secondary cycle and the establishment of the key schools. The purpose is to prepare a higherlevel syllabus for use in the key schools and a lower-level one, consisting of a core of basic knowledge, that will be available to the majority of students.

Current policy now favors the introduction of science in primary schools. In grades 1 to 4 , science is presented one period per week, and in grades 5 and 6 for two periods per week. This accounts for about 5 percent of curriculum time.

At the secondary level, physics, chemistry, and biology with some health science are taught throughout as separate subjects. The emphasis given these areas of study varies depending on whether the school is a key school, whether it has single streams or divides classes 
into liberal arts and science, and whether it is vocationally or agriculturally oriented.

Teaching method

Methods of teaching depend heavily on the use of lectures and demonstrations. The obvious advantages of this method need to be balanced against the effect of this kind of pedagogy on learning. Much recent curriculum development in science outside China has been based on the belief that students learn science most effectively through direct experience and with the opportunity to experiment for themselves. It is widely held that such learning is more durable, is more likely to increase the motivation of students, and helps students develop their own powers of reasoning, problem solving, prediction, critical observation, and analysis.

\section{Entrance examination}

Practical examinations are rare and are not normally part of formal assessment procedures. Over 70 percent of questions set at the secondary level are closely based on material in the textbooks and are designed to be answered primarily on the basis of the recall of knowledge. Twenty percent of the questions are designed to tap deeper levels of understanding, and the remaining 10 percent are intended only for the very best students (Lewin, 1987).

Teacher training in science

About 17 percent of secondary teachers are currently teaching science, and about 70 percent of these are in the junior middle schools. However, 29 percent of primary teachers, 59 percent of junior high, and 56 percent of senior high teachers are said to be untrained. Many entered the teaching profession during the Great Proletarian Cultural Revolution (Young, 1992). Science teacher training is organized through a number of different channels. In brief, upper secondary teachers are now trained at the "normal" universities. Lower secondary 
teachers are trained through a very large number of training institutes and colleges. Elementary teachers are trained at junior teacher colleges. The courses that students follow in teacher training closely resemble those offered by academic universities. There is far less course differentiation for teachers in training than is common in the United Kingdom or the United States.

\section{Issues and trends}

Under the Great Proletarian Cultural Revolution, teachers and intellectuals were regarded with suspicion, and many were persecuted and regarded as the source of counterrevolutionary tendencies. "Experts" and expertise were not valued by the counterrevolutionaries. Since 1976, the national climate has changed, and a number of campaigns have been mounted to improve the public recognition of the teacher's role in society. Graduate students sometimes refer to primary school teachers as "not much above the level of road sweepers" (Lewin, 1987). This is perhaps appropriate since the remuneration that primary teachers receive of 71209 Yuan per month is comparable to that of workers in the lowest segments of the labor market (Young, 1992). Research on middle school students suggests that teaching is still an unpopular occupation since only 2.8 percent of these students selected teaching when asked about their career aspirations (Lewin, 1987). There is a compelling need to examine ways in which the teaching profession can be made more attractive to able secondary school students. It is important to improve the academic level of entrants to training courses and to encourage a greater proportion of them to become teachers.

\section{Science Education in Taiwan}

Owing to the efforts and industry of the people and a rapid growth in the national economy, education has made spectacular progress in free China along with rapid growth of the national economy in the past thirty-five years. Beginning with the school year 1968-1969, the period 
of mandatory free education in the Republic of China was extended from six to nine years.

The school system

The total period of study from kindergarten to graduate school is 22 years or more including 2 years for preschool education, 6 years for elementary education, 3 years for junior high school education, 3 years for senior high school education, 4-7 years for college or university education, 2 years or more for earning a master's degree in a graduate school, and 2 years or more for getting a doctoral degree.

In senior vocational schools, students can study agriculture, industry, commerce, marine products, nursing and midwifery, home economics, and Chinese opera. Junior college education is divided into two categories according to the qualifications of the students. The 5year junior college admits junior high school graduates for a study period of 5 years, whereas a normal college admits graduates from senior secondary schools for a study period of 3 or 4 years. After completing their studies, these students may apply to the Institute of Technology for advanced study.

Normal education, a 4-year period of study for senior secondary graduates, is divided into two levels. The junior normal college trains elementary school teachers. Normal colleges and normal university train secondary school teachers. One additional year of practice teaching is also mandatory.

University and college education is for the purpose of earning a bachelor's degree. The period of study is 4 years except for law and medicine, in which the study period ranges from 5 to 7 years (including internship). Only holders of a bachelor's degree are eligible to be admitted to graduate schools to work for the master's degree; only holders of a master's degree are admitted to graduate schools to work for the doctoral degree. The period of study for both categories is not less than 2 years.

Evening sessions affiliated with colleges or universities have a period of study of one more year than does the day school. At present, only elementary school departments and junior and senior vocational 
departments are provided for education of the blind, deaf, and other physically handicapped or mentally retarded youths. The period of study is the same as the corresponding time in ordinary schools.

High school and university entrance examinations

This year in the Taipei area there were approximately 62,000 junior high school graduates who wanted to enter 13 public high schools which could accommodate only 23,000 students. There were 124,654 senior high graduates who wanted to enter 60 universities and colleges which could accommodate only 52,098 students. To avoid an unfair situation, an entrance examination is required. The High School Entrance Examination is set by each provincial educational division. The University and College Entrance Examination is set by the national educational division. In these entrance examinations, students who score higher may choose the more desirable schools. Entrance into the best schools is highly competitive.

Descriptions of classroom and teaching situations

The common comment about education in free China is that "the entrance examination directs the instruction," because the contents and styles of entrance examinations determine the style and emphasis of instruction. Parents in Taiwan pay a lot of attention to their children's education, hoping their children can have a better education so they can have an easier life and a higher social position than the parents did. Educators have a high social position and receive great respect (Lin, 1992).

Because of the competition in education, private tutors and private supplementary schools are very popular. When students finish seven hours of classes in school, they go for two to three hours of extra exercise or instruction by private tutors or to private supplementary schools.

In Taiwan the students begin a heavy academic work load in the first grade of elementary school. For example, in the first year they will learn 


\section{Iris Huang}

to read, write, use three hundred Chinese characters, and perform the addition of one- and two-digit numbers.

To teach more efficiently, management of classrooms is very important. From elementary classes to high school, there are about forty-five students in each classroom. The tables and chairs are arranged in rows, and all students face the platform at the front of the room. Students remain silent in the classroom unless called upon by the teacher. Students in Taiwan are accustomed to being quiet and paying attention to the teacher's instruction. Usually they do not ask questions. Most teachers use the one way lecture to accommodate large numbers of students in a short period.

To express respect and gratefulness to teachers, there is a holiday called Teacher's Day. Usually, before the class starts, and as the teacher enters the classroom, the leader says "stand up." All the students then stand and salute the teacher, and sit down to start the class. Most students feel that they should not bother the teacher. The relationship of students to teachers blends respect with a small amount of fear.

Science curriculum

The curricula and standards of different levels of schools are set by the Ministry of Education. Natural science is taught in grades 1 and 2 for two periods per week, and in grades 3-6 for three periods per week. There is biology in grade 7 for three periods per week and physical science in grades 8 and 9 for four periods per week. Students in the first grade of senior high are required to study at least two of the four sciences (fundamental biology, fundamental chemistry, fundamental physics, and fundamental earth science) each semester. In the second and third grades of senior high school, a student can select o-3 subjects from biology, physics chemistry, and earth science according to the anticipated university major.

Science teacher education

Teacher education is divided into two levels. The first level of education, designed to train teachers for elementary schools and 
kindergartens, is offered by teachers colleges, which admit senior high (vocational) graduates to a four-year program. The second level of education, designed to train teachers for secondary schools, is offered by normal universities, which admit senior secondary graduates to a four-year educational program. Normal universities, teachers colleges, and other public and private universities all participate in educating teachers.

Issues and reforms

In 1994, amid voices calling for education reforms, a number of important measures were implemented. A program to promote 'priority education districts ' was drawn up to pursue a balance between urban and rural areas. A "ten-year national compulsory based on a vocational education program" was drawn up to relieve the pressure on junior high students. The University Law was amended to make universities more democratic. The Teacher Education Law was enacted to diversify the education of teachers.

Implication and Conclusion

In the last fifteen years, the Asian region's production of natural science and engineering degrees has grown dramatically, as have its economy, its investment in research and development, and its attendant need for scientists and engineers. Knowing more about science education in Asia enables us to improve it. The challenges ahead are apparent. Scientists, as well as world leaders, must understand other cultures if they wish to share ideas and values, transfer technology, establish personal relationships, and help tomorrow's leaders in the quest for a peaceful and equitable global existence.

\section{References}

China Handbook Editorial Committee (1983). Education and Science, Beijing: Foreign Language Press. 
Hsiung, C., \& Tuan, H. (In Press). Science teacher education in selected countries in Asia. In K. Tobin \& B. Fraser (Eds.) International Handbook of Science Education. Dordrecht: Kluwer Publishers.

Johnson, J.M. (1993). Human Resources for Science and Technology: The Asian Region. Paper presented at the Annual Meeting of the American Educational Research Association, Atlanta, GA.

Lee, M.L. (1992). The Analysis of Compulsory Education in Mainland China. In Chinese Comparative Education Association (Ed.), Comparative Study of Education Development of Two Chinas. Taipei: Normal University Book Company. (In Chinese).

Lewin, K.M. (1987). Science education in China: Transformation and change in the 1980s. Comparative Education Review, 31, 419-441.

Lin, C.J. (1992). The study of teachers' professional image and occupational prestige in the Republic of China. In Chinese Comparative Education Association (Ed.), Comparative Study of Education Development of Two Chinas. Taipei: Normal University Book Company, (In Chinese).

Liu, S.J. (1992). The prospect of private higher education in Mainland China. In Chinese Comparative Education Association (Ed.), Comparative Study of Education Development of Two Chinas. Taipei: Normal University Book Company, (In Chinese).

Ministry of Education (1994). Education in the Republic of China. Taipei: Ministry of Education.

Wei, M.T., Fan, T.S., \& Lee, H.S. (1995). The Study of Science and Technology Education in Mainland China. Report of the Committee of Mainland China, Taipei, Taiwan. (In Chinese).

Wu, C. (1990). The Development of Asian University: From Dependence to Independence. Taipei: Normal University Book Company. (In Chinese). 